\title{
Acute illness, Comorbidity and Mortality in a Norwegian Intensive Care Population
}

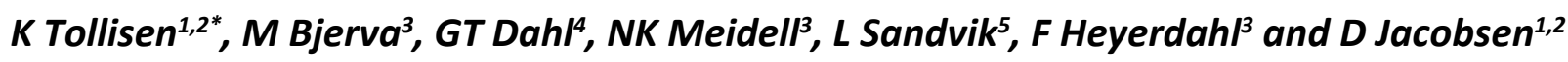 \\ ${ }^{1}$ Institute of Clinical Medicine, University of Oslo, Norway \\ ${ }^{2}$ Department of Acute Medicine, Oslo University Hospital, Norway \\ ${ }^{3}$ Department of Anesthesiology, Oslo University Hospital, Norway \\ ${ }^{4}$ Department of Anesthesiology, Diakonhjemmet Hospital, Norway \\ ${ }^{5}$ Oslo Centre for Biostatistics and Epidemiology, Norway
}

*Corresponding author: Karen Hunting Tollisen, MD, University of Oslo c/o Oslo University Hospital Ullevaal, P.O. Box 4956 Nydalen, 0424 Oslo, Norway, Tel: +47-416-972-79, Fax: +47-221-191-81

\begin{abstract}
Background: The need for intensive care beds is high and expected to increase. Descriptive studies of the intensive care population may reveal differences in predisposing factors and outcome within subgroups and help identify areas in need of increased prevention efforts.
\end{abstract}

Objective: To describe preadmission and clinical characteristics of an intensive care population in Oslo, and to compare the characteristics and outcomes of selected subgroups of this ICU-population.

Method: Prospective observational cohort study of intensive care patients aged $\geq 18$, admitted to two hospitals in Oslo during a one-year period. Acute illness characteristics, co-morbidity, limitations of life-sustaining treatment and hospital mortality were studied for the overall population and stratified for a) Gender and b) Medical and surgical patients within the age groups 18-59 years and 60 and above.

Results: We included 861 patients, 567 (66\%) males; median age 63 years (range 18-95); 537 (62\%) medical admissions and $324(38 \%)$ surgical admissions. 632 $(73 \%)$ received mechanical ventilation. Trauma $(n=191$, $21 \%)$ and cardiovascular disease $(n=180,20 \%)$ were the most common causes of admission. In patients aged $18-59$, poisoning caused $56 / 217(26 \%)$ of the medical admissions and medical patients had a higher prevalence of pre-existing chronic disease $(157 / 217,72 \%$ vs. $69 / 160$, $43 \%$ ) and Charlson comorbidity index (mean 2.0 vs. 0.7 , $p<0.001)$ than surgical patients. In patients aged 60 and above, comorbidity was similar, but medical patients had a higher hospital mortality $(143 / 320,45 \%$ vs. $58 / 164,34 \%$, p < 0.05). 205 (24\%) died in the ICU, and limitations of life-sustaining treatment were made in $183(89 \%)$ cases $279(32 \%)$ died during the hospital stay. Of the 582 surviving patients $455(78 \%)$ were discharged to home or rehabilitation, $88(15 \%)$ to nursing homes and $39(7 \%)$ to other institutions.

Conclusion: In patients younger than 60 years, trauma and poisoning were the most common causes of admission. Within this age group, medical patients had much higher prevalence of preexisting chronic disease than surgical patients, suggesting differences in predisposing factors. The majority of the surviving patients were discharged to home or to rehabilitation, indicating a low prevalence of futile intensive care.

\section{Introduction}

Intensive care units (ICU) provide advanced health care for seriously injured and ill patients, demanding vast economic resources. The population is aging and the need for intensive care beds is expected to increase considerably over the next decades [1]. This will have serious implications for planning and financing of the health care system. Descriptive studies of intensive care patients are needed to ensure that the health services can meet future needs [2].

Evaluation of ICU services are challenging due to variations in ICU-beds availability and case-mix in different intensive care populations. The selection of pa-

Citation: Tollisen K, Bjerva M, Dahl GT, Meidell NK, Sandvik L, et al. (2019) Acute illness, Co-morbidity and Mortality in a Norwegian Intensive Care Population. Int J Anesthetic Anesthesiol 6:084. doi. org/10.23937/2377-4630/1410084

Accepted: February 14, 2019: Published: February 16, 2019

Copyright: (c) 2019 Tollisen K, et al. This is an open-access article distributed under the terms of the Creative Commons Attribution License, which permits unrestricted use, distribution, and reproduction in any medium, provided the original author and source are credited. 
tients may also vary between local and regional hospitals and these differences are important to address when studying ICU patients. Patients with medical and surgical admissions are often treated in specialized ICUs and may have different needs. Thus, separate description of medical and surgical ICU patients may be useful in the planning of future intensive care treatment.

Age, co-morbidity and severity of illness are important predictors of mortality in intensive care patients [3]. Since co-morbidity increases significantly with age [4], stratification in age groups is important when describing ICU populations. Comparison of the characteristics of medical and surgical patients - within age groups may reveal differences in predisposing factors, comorbidity factors and outcome [5] that may help identify areas in need of increased prevention efforts.

On this background our study had the following aims:

1. To describe the age and gender distribution, comorbidity factors, diagnostic categories, limitations of life-sustaining treatment and hospital mortality of a mixed ICU population in Oslo.

2. To compare a) Male and female patients and b) Medical and surgical patients within age groups on selected parameters.

\section{Material and Methods}

\section{Study design and population}

The study had a prospective observational cohort design and included intensive care patients admitted to the intensive care units (ICUs) at the Oslo University hospital Ullevaal and the Diakonhjemmet Hospital in the period February $3^{\text {rd }} 2014$ to February $2^{\text {nd }} 2015$. The Oslo University hospital Ullevaal is a tertiary referral hospital with comprehensive medical services including trauma, neurosurgery and percutaneous cardiac intervention for Eastern Norway (3.0 million inhabitants). In addition, it serves as a local hospital for one third of Oslo's population (647,676 inhabitants; 2015).

The Diakonhjemmet hospital serves as a local hospital for 115,000 inhabitants in Oslo. Five intensive care units participated in the study; the medical, cardiac, surgical and neurosurgical ICUs at the Oslo Universitiy hospital, Ullevaal and the mixed medical/surgical intensive care unit at the Diakonhjemmet hospital (Table 1). Since the post-operative units at the study hospitals did not participate in the study, no patients with elective thoracic or cardiac surgery were included. In order to avoid individuals being represented multiple times, only the first admission of each patient during the study period was registered.

Inclusion criterias were age $\geq 18$ years and 1 ) Intubation regardless of length of stay and/or 2) ICU length of stay $\geq 24$ hours, and dysfunction of $\geq$ two organ systems (see Appendix). Of the 995 ICU-admissions filling the inclusion criteria (Figure 1), 91 patients were excluded due to missing consent or language problems. Median age for these patients was 54 (range 18-89), and $63 \%$ were males. Of the remaining 904 admissions, 43 (4\%) were readmissions of previously included patients and therefore excluded from the analysis.

\section{Ethics}

Ethics approval was granted by the Norwegian Regional Ethics Committee (REK), case number 2012/12601. Informed consent was given by the patient or next of kin. Exceptions were made for patients 1) Unable to give their consent themselves without next of kin that could be asked instead 2) Admitted with acute poisoning and 3) Who died during ICU treatment.

\section{Stratification}

The material was stratified into medical and surgical admissions as defined by the SAPS II system: 1) Medical: No surgery within 1 week prior to ICU admission. 2) Surgical: a) Scheduled surgical patients - elective surgery within 7 days of ICU admission and b) Non-scheduled surgical patients: acute surgery (scheduled less than 24 $\mathrm{h}$ in advance) within 1 week prior to ICU admission. The World Health Organization define patients above 60 years as elderly. We therefore subdivided the patients in age groups 18-59 and 60 and above.

\section{Registrations}

Data were consecutively collected using a standardized registration form and included the following variables: Age; gender; preadmission living situation (living at home without home care (selfreliant), living at home with home care, nursing home etc.); Charlson comorbidity index (C.I.I) [6]; main diagnostic category based on the APACHE system;

Table 1: Description of the ICUs participating in the study.

\begin{tabular}{|r|l|l|l|}
\hline Intensive care units & ICU beds & Number of admissions pr. year & Nurse: Patient ratio \\
\hline Oslo University Hospital, Ullevaal & & & $1.3: 1$ \\
\hline 1. Medical & 6 & 450 & $1: 1$ \\
\hline 2. Cardiac & 3 & 150 & $2: 1$ \\
\hline 3. Surgical, general & 10 & 420 & $2: 1$ \\
\hline 4. Neurosurgical & 6 & 220 & $1: 1$ \\
\hline Diakonhjemmet Hospital & & & \\
\hline 5. Mixed general & 4 & 300 & \\
\hline Total & 29 & $1540^{*}$ & \\
\hline
\end{tabular}

${ }^{*}$ Numbers pr. 2018. 
SAPS II score [7]; SOFA (sequential organ dysfunction assessment) [8] at admission; length of stay; mechanical ventilator support; duration of mechanical ventilation; non-invasive ventilator support; renal replacement therapy; post-discharge location (home, nursing home etc.); ICU-mortality and total hospital mortality (ICU-mortality included). For patients who died in the ICU, we registered decisions regarding limitations of life-sustaining treatment including a) Withholding treatment (the decision not to start or increase a life-

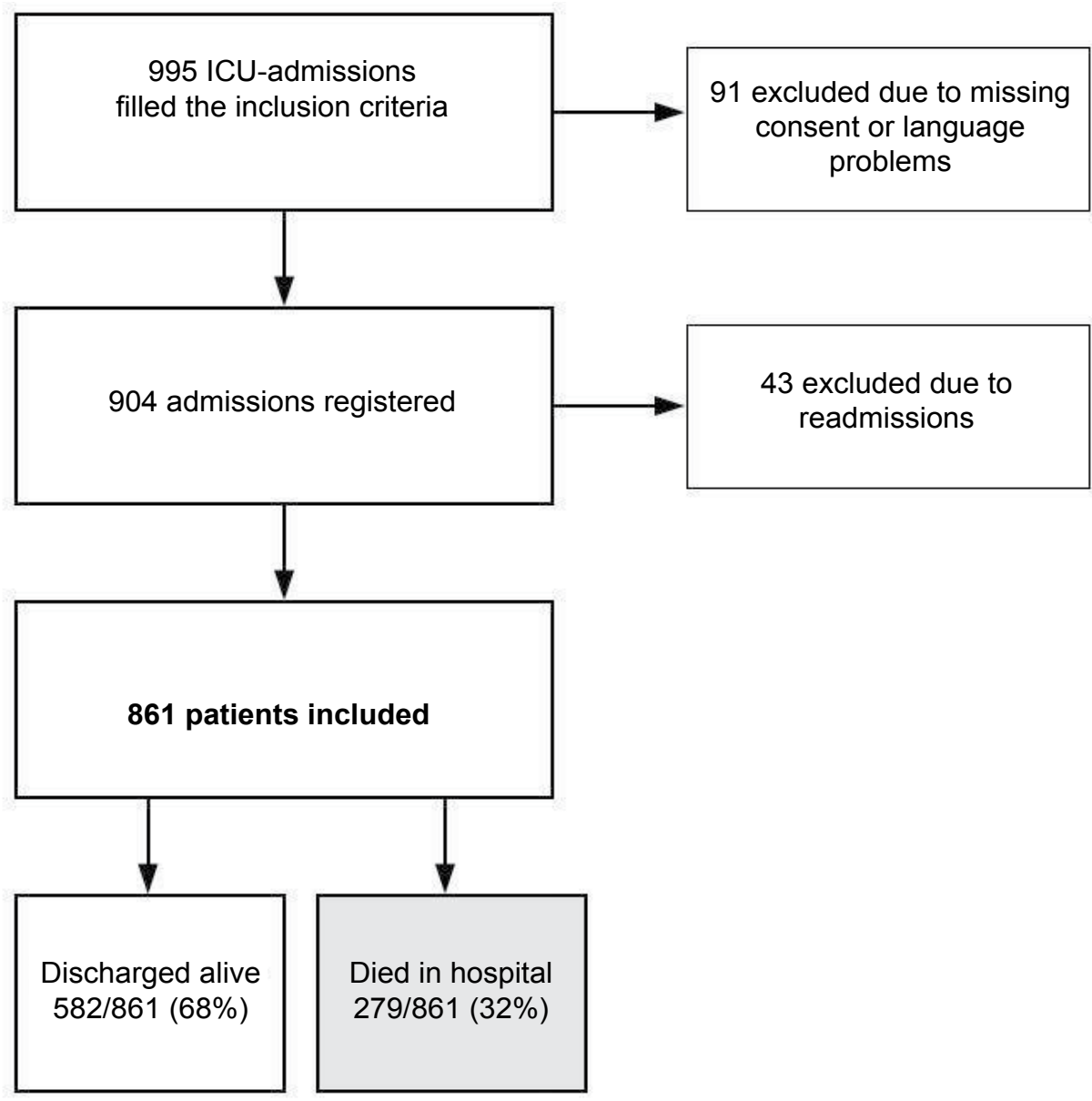

Figure 1: Flow-chart of the patients included in the study.

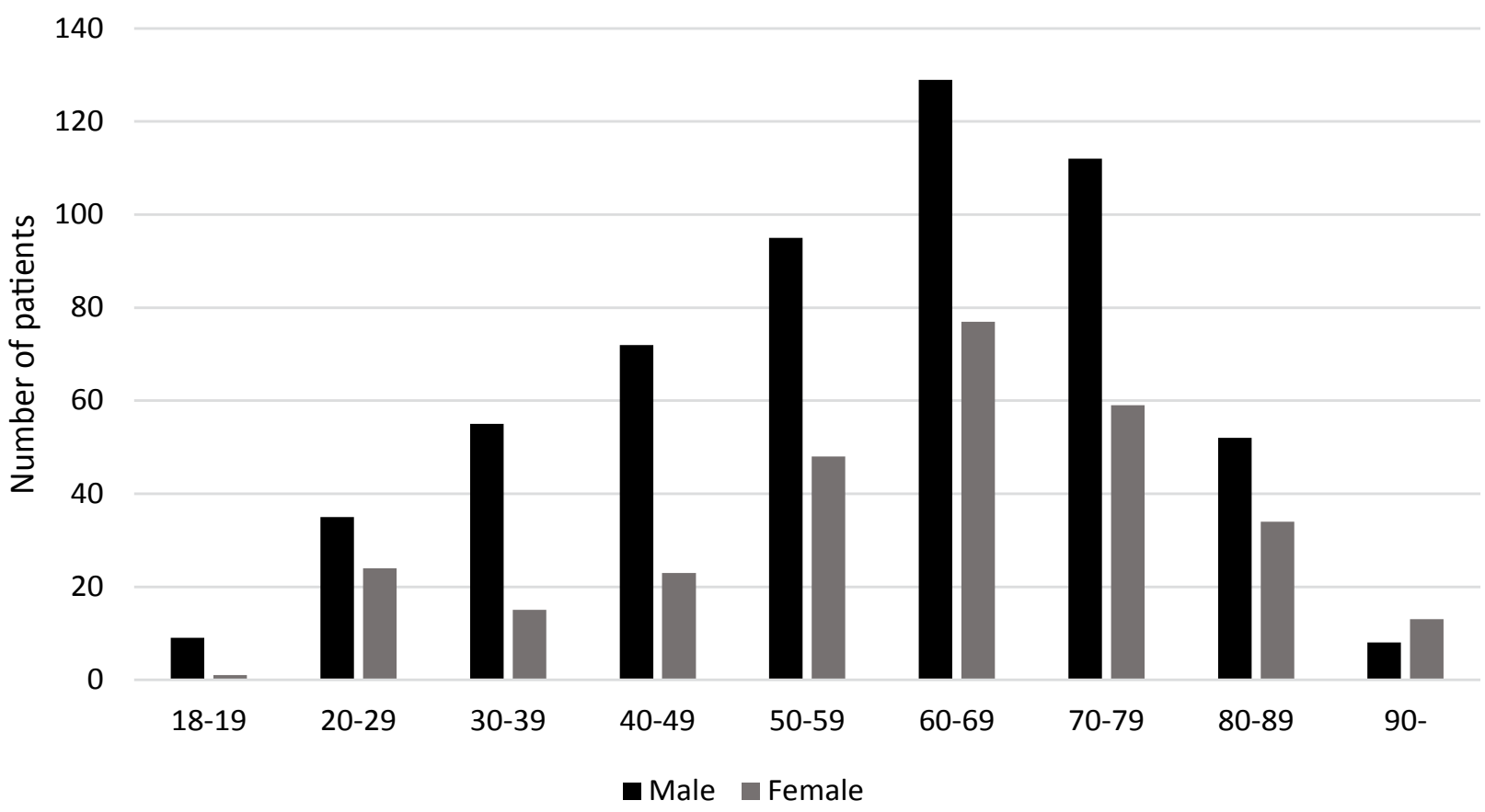

Figure 2: Distribution of male/female patients within age groups. 
sustaining intervention) or b) Withdrawing treatment (the decision to stop a life-sustaining intervention) [9].

\section{Statistics}

Chi square test was used when comparing proportions and an independent samples t-test was used when comparing means. IBM SPSS ${ }^{\circledR}$ version 25.0 for Windows (Armonk, NY, USA) was used for the statistical analysis. $P$ values $<0.05$ were considered statistically significant.

\section{Results}

\section{Study population}

Of the 861 patients included (Figure 1), 567 (66\%) were males, 537 (62\%) were medical admissions and 324 (38\%) were surgical admissions, of which 27 were scheduled and 297 non-scheduled. Median age was 63 years (range 18-95). Male patients were younger than female patients (median age 61 vs. $64, p=0.03$ ), and were in majority within all age groups except for patients aged 90 and above (Figure 2). Surgical patients were younger than medical patients (median age 60 vs. $64, p<0.01)$.

Characteristics of the overall study population stratified for medical and surgical patients, are presented in Table 2, Table 3, Table 4 and Table 5.

Overall, mean Charlson comorbidity index (CCI) was 2.3, and 672 (78\%) of the patients had pre-existing chronic disease at admission (Table 2). In the age group 18-59, medical patients had higher mean Charlson co-morbidity index (CCl) (2.0 vs. 0.7, $\mathrm{p}<0.001$ ) and prevalence of pre-existing chronic disease than surgical patients $(157 / 217,72 \%$ vs. 69/160, 43\%, $p<0.001)$. Comorbidity was similar in the age group 60 and above and between the genders. Of the patients included,

Table 2: Pre-admission characteristics.

\begin{tabular}{|c|c|c|c|c|c|}
\hline & \multirow{2}{*}{$\begin{array}{l}\text { All patients } \\
\mathrm{N}=861\end{array}$} & \multicolumn{2}{|c|}{$18-59$ years $(n=377)$} & \multicolumn{2}{|c|}{60 years and above $(n=484)$} \\
\hline & & $\begin{array}{l}\text { Medical } \\
n=217\end{array}$ & $\begin{array}{l}\text { Surgical } \\
n=160\end{array}$ & $\begin{array}{l}\text { Medical } \\
n=320\end{array}$ & $\begin{array}{l}\text { Surgical } \\
n=164\end{array}$ \\
\hline Males n (\%) & $567(66 \%)$ & $145(67 \%)$ & $121(75 \%)$ & $199(62 \%)$ & $102(62 \%)$ \\
\hline $\begin{array}{l}\text { Charlson co-morbidity index, mean } \pm \\
\text { SD }\end{array}$ & $2.3 \pm 2.2$ & $2.0 \pm 2.2$ & $0.7 \pm 1.3^{*}$ & $3.0 \pm 2.2$ & $2.7 \pm 2.1$ \\
\hline \multicolumn{6}{|l|}{ Chronic disease $\mathrm{n}(\%)$} \\
\hline Known chronic disease & $672(78 \%)$ & $157(72 \%)$ & $69(43 \%)^{*}$ & $298(93 \%)$ & $148(90 \%)$ \\
\hline No prior chronic disease & $189(22 \%)$ & $60(28 \%)$ & $91(57 \%)^{*}$ & $22(7 \%)$ & $16(10 \%)$ \\
\hline \multicolumn{6}{|l|}{ Common chronic disease categories $^{1}$} \\
\hline Cardiovascular disease $\mathrm{n}(\%)$ & $343(40 \%)$ & $45(21 \%)$ & $21(13 \%)$ & $195(61 \%)$ & $82(50 \%)$ \\
\hline Chronic pulmonary disease $\mathrm{n}(\%)$ & $167(20 \%)$ & $24(11 \%)$ & $9(6 \%)$ & $101(32 \%)$ & $33(21 \%)$ \\
\hline Diabetes n (\%) & $136(16 \%)$ & $29(13 \%)$ & $4(3 \%)$ & $70(22 \%)$ & $33(20 \%)$ \\
\hline \multicolumn{6}{|l|}{ Polyfarmacy, regular medication $\mathrm{n}(\%)$} \\
\hline None & $213(25 \%)$ & $70(32 \%)$ & $97(61 \%)^{*}$ & $27(9 \%)$ & $19(12 \%)$ \\
\hline $1-4$ & $358(42 \%)$ & $93(43 \%)$ & $49(31 \%)$ & $113(35 \%)$ & $102(62 \%)$ \\
\hline $5-7$ & $145(17 \%)$ & $26(12 \%)$ & $8(5 \%)$ & $85(27 \%)$ & $26(16 \%)$ \\
\hline$\geq 8$ & $145(17 \%)$ & $28(13 \%)$ & $6(4 \%)$ & $94(29 \%)$ & $17(10 \%)$ \\
\hline \multicolumn{6}{|l|}{ Living situation n (\%) } \\
\hline Home without home care & $679(79 \%)$ & $178(82 \%)$ & $143(89 \%)^{*}$ & $221(69 \%)$ & $137(84 \%)^{*}$ \\
\hline Home with home care & $90(10 \%)$ & $13(6 \%)$ & $2(1 \%)$ & $63(20 \%)$ & $12(7 \%)$ \\
\hline Nursing home or institution & $50(6 \%)$ & $6(3 \%)$ & $0(0 \%)$ & $30(9 \%)$ & $14(9 \%)$ \\
\hline Homeless & $11(1 \%)$ & $6(3 \%)$ & $4(2 \%)$ & $1(0.3 \%)$ & 0 \\
\hline Other $^{2}$ & $24(3 \%)$ & $11(5 \%)$ & $8(6 \%)$ & $4(1 \%)$ & 0 \\
\hline Unknown & $8(1 \%)$ & $3(1 \%)$ & $3(2 \%)$ & $1(0.3 \%)$ & $1(0.6 \%)$ \\
\hline
\end{tabular}

${ }^{1}$ Each patient may have more than one disease; ${ }^{2}$ Incl. psychiatric and drug abuse institutions; " $p<0.05$.

Table 3: Main diagnostic categories $\mathrm{n}(\%)$.

\begin{tabular}{|c|c|c|c|c|c|}
\hline \multirow[b]{2}{*}{$\begin{array}{l}\text { Main diagnosic } \\
\text { categories } \mathrm{n}(\%)\end{array}$} & \multirow[t]{2}{*}{ All patients $\mathbf{N}=\mathbf{8 6 1}$} & \multicolumn{2}{|c|}{$18-59$ years $(n=377)$} & \multicolumn{2}{|c|}{60 years and above $(n=484)$} \\
\hline & & Medical $n=217$ & Surgical $n=160$ & Medical $n=320$ & Surgical $n=164$ \\
\hline Trauma & $191(22 \%)$ & 0 & $119(74 \%)$ & 0 & $72(44 \%)$ \\
\hline Cardiovascular disease & $180(21 \%)$ & $47(22 \%)$ & $3(2 \%)$ & $124(39 \%)$ & $6(4 \%)$ \\
\hline Sepsis & $116(13 \%)$ & $41(19 \%)$ & $2(1 \%)$ & $63(20 \%)$ & $10(6 \%)$ \\
\hline Respiratory & $88(10 \%)$ & $16(7 \%)$ & $3(2 \%)$ & $53(17 \%)$ & $16(10 \%)$ \\
\hline Gastrointestinal & $81(10 \%)$ & $17(8 \%)$ & $12(8 \%)$ & $17(5 \%)$ & $35(21 \%)$ \\
\hline Neurologic/CNS & $73(8 \%)$ & $22(10 \%)$ & $12(8 \%)$ & $27(8 \%)$ & $12(7 \%)$ \\
\hline Poisoning & $65(8 \%)$ & $56(26 \%)$ & 0 & $9(3 \%)$ & 0 \\
\hline Cancer & $23(3 \%)$ & $4(2 \%)$ & $4(3 \%)$ & $5(2 \%)$ & $10(6 \%)$ \\
\hline Other & $44(5 \%)$ & $14(7 \%)$ & $5(3 \%)$ & $22(7 \%)$ & $3(2 \%)$ \\
\hline
\end{tabular}


Table 4: Severity of illness and treatment.

\begin{tabular}{|c|c|c|c|c|c|}
\hline & \multirow[t]{2}{*}{ All patients $(\mathrm{N}=\mathbf{8 6 1})$} & \multicolumn{2}{|c|}{$18-59$ years $(n=377)$} & \multicolumn{2}{|c|}{60 years and above $(n=484)$} \\
\hline & & $\begin{array}{l}\text { Medical } \\
n=217\end{array}$ & $\begin{array}{l}\text { Surgical } \\
n=160\end{array}$ & $\begin{array}{l}\text { Medical } \\
n=320\end{array}$ & $\begin{array}{l}\text { Surgical } \\
n=164\end{array}$ \\
\hline SAPS II, mean \pm SD & $46.0 \pm 18$ & $41.7 \pm 19$ & $39.0 \pm 14$ & $52.3 \pm 19$ & $46.8 \pm 16^{*}$ \\
\hline SOFA admission, mean \pm SD & $7.4 \pm 3.5$ & $7.1 \pm 4$ & $6.8 \pm 3$ & $7.7 \pm 4$ & $7.4 \pm 3$ \\
\hline $\begin{array}{l}\text { ICU-length of stay (LOS), median } \\
\text { days (IQR) }\end{array}$ & $4.5(1.9-9.8)$ & $3.5(1.3-7.7)$ & $6.2(2.3-14.5)^{*}$ & $3.7(1.8-7.3)$ & $6.9(3.0-14.5)^{\star}$ \\
\hline $\begin{array}{l}\text { Transferred to other hospital during } \\
\text { ICU-stay, n (\%) }\end{array}$ & $214(25 \%)$ & $52(24 \%)$ & $43(27 \%)$ & $76(24 \%)$ & $43(26 \%)$ \\
\hline Intubated patients, n (\%) & $632(73 \%)$ & $152(70 \%)$ & $158(99 \%)^{*}$ & $164(51 \%)$ & $158(96 \%)^{*}$ \\
\hline $\begin{array}{l}\text { Mechanical ventilator support time, } \\
\text { days, median(IQR) }\end{array}$ & $3(1-8.4)$ & $2.8(0.5-7.0)$ & $2.0(0.5-10.0)$ & $3.0(1.1-7.0)$ & $4.0(1.0-10.6)$ \\
\hline Non-invasive ventilator support $\mathrm{n}(\%)$ & $227(26 \%)$ & $46(21 \%)$ & $22(14 \%)$ & $129(40 \%)$ & $30(18 \%)^{*}$ \\
\hline Renal replacement therapy $n(\%)$ & $91(11 \%)$ & $38(17 \%)$ & $12(8 \%)^{*}$ & $26(8 \%)$ & $15(9 \%)$ \\
\hline Vasopressor therapy n (\%) & $575(67 \%)$ & $117(53 \%)$ & $121(75 \%)^{*}$ & $202(63 \%)$ & $135(82 \%)^{*}$ \\
\hline \multicolumn{6}{|l|}{ Sepsis $^{1}$} \\
\hline Total n (\%) & $210(24 \%)$ & $61(28 \%)$ & $26(16 \%)$ & $84(26 \%)$ & $39(24 \%)$ \\
\hline \multicolumn{6}{|l|}{ Primary source: } \\
\hline Respiratory n (\%) & $88(10 \%)$ & $28(13 \%)$ & $5(3 \%)$ & $45(14 \%)$ & $10(6 \%)$ \\
\hline Abdominal organs $\mathrm{n}(\%)$ & $45(5 \%)$ & $4(2 \%)$ & $11(7 \%)$ & $9(3 \%)$ & $21(13 \%)$ \\
\hline Soft tissue n (\%) & $25(3 \%)$ & $11(5 \%)$ & $5(3 \%)$ & $7(2 \%)$ & $2(1 \%)$ \\
\hline Urinary tract $\mathrm{n}(\%)$ & $19(2 \%)$ & $4(2 \%)$ & 0 & $14(4 \%)$ & $6(1 \%)$ \\
\hline Catheter-related infection $\mathrm{n}(\%)$ & $11(1 \%)$ & $4(2 \%)$ & $2(1 \%)$ & $4(1 \%)$ & $6(1 \%)$ \\
\hline CNS n (\%) & $11(1 \%)$ & $6(2 \%)$ & $3(2 \%)$ & $2(1 \%)$ & 0 \\
\hline Endocarditis n (\%) & $5(0.5 \%)$ & $3(1 \%)$ & 0 & $1(1 \%)$ & $1(1 \%)$ \\
\hline Other n (\%) & $2(0.2 \%)$ & 0 & 0 & $1(0.5 \%)$ & $1(0.5 \%)$ \\
\hline Origin unknown n (\%) & $9(1 \%)$ & $4(2 \%)$ & 0 & $3(1 \%)$ & $2(1 \%)$ \\
\hline
\end{tabular}

${ }^{1}$ Sepsis as main diagnose $(n=116)$ or complication $(n=94) .{ }^{*} p<0.05$

$679(79 \%)$ were self-reliant without home care services before admission. The proportion of self-reliant patients was higher in surgical than medical patients (178/217, 82\% vs. $143 / 160,89 \%, p<0.05$ and $137 / 164$, $84 \%$ vs. $221 / 320,69 \%, p<0.01$ respectively) and in male compared to female patients $(460 / 567,81 \%$ vs. $219 / 294,74 \% \mathrm{p}<0.03)$. Overall, mean SAPS II was 46 , and mean SOFA score at admission 7.4.

\section{Diagnostic categories}

Trauma and cardiovascular disease were the most common diagnoses (Table 3). Average age differed markedly between the diagnostic categories (Figure 3). The categories trauma and poisoning were dominated by younger patients (median age 53 and 41. respectively). Poisoning caused 56/217 (26\%) of the medical admissions in the age group 18-59 (Table 3), and 30/65 (46\%) in the subgroup below 40 years. Trauma caused $119 / 160(74 \%)$ of the surgical admissions in patients aged 18-59 (Table 3 ), and 56/75 (75\%) of the subgroup below 40 . In the age group 60 and above, the most common diagnoses in medical patients were cardiovascular disease $(124 / 320,39 \%)$ and sepsis (63/320, 20\%). Trauma (72/164, 44\%) and gastrointestinal disease $(35 / 164,21 \%)$ were the most common diagnoses in surgical patients.

Male patients were in majority within all diagnostic categories. Trauma and cardiovascular disease had the highest proportion of males ( $75 \%$ and $76 \%$, respectively).

$210 / 861(24 \%)$ of the study sample had sepsis (Table $4)$, either as the main diagnosis ( $n=116)$ or complication. Respiratory infection was the most common primary source of sepsis in medical patients of both age groups, as opposed to abdominal infection in surgical patients.

\section{Treatment}

Overall, 632 (73\%) patients received mechanical ventilation (Table 4) The proportion of intubated patients were significantly higher in males than in females (438/567, $77 \%$ vs. $194 / 294,66 \%, p<0.01$ ). Across the age groups, more surgical than medical patients received mechanical ventilation (158/160, $99 \%$ vs. $152 / 217,70 \%, p<0.001$ and $158 / 164,96 \%$ vs. $164 / 320,51 \%, p<0.001)$ as well as vasopressor therapy $(121 / 160,75 \%$ vs. $117 / 217,53 \%, p<0.001$ and $135 / 164,82 \%$ vs. $202 / 320,63 \%, p<0.001)$. Noninvasive ventilation was more frequently used in the treatment of medical patients, but the difference was only significant in the age group 60 and above (129/320, $40 \%$ vs. $30 / 164,18 \%, p<0.001)$. In the age group $18-59$, the proportion of patients receiving renal replacement therapy (RRT) was more than twice as high in medical compared to surgical patients (38/219, $17 \%$ vs. $12 / 161$, $8 \%, p<0.01)$. There was no difference in the proportion receiving RRT among patients above 60 .

In both age groups, median length of stay in the 


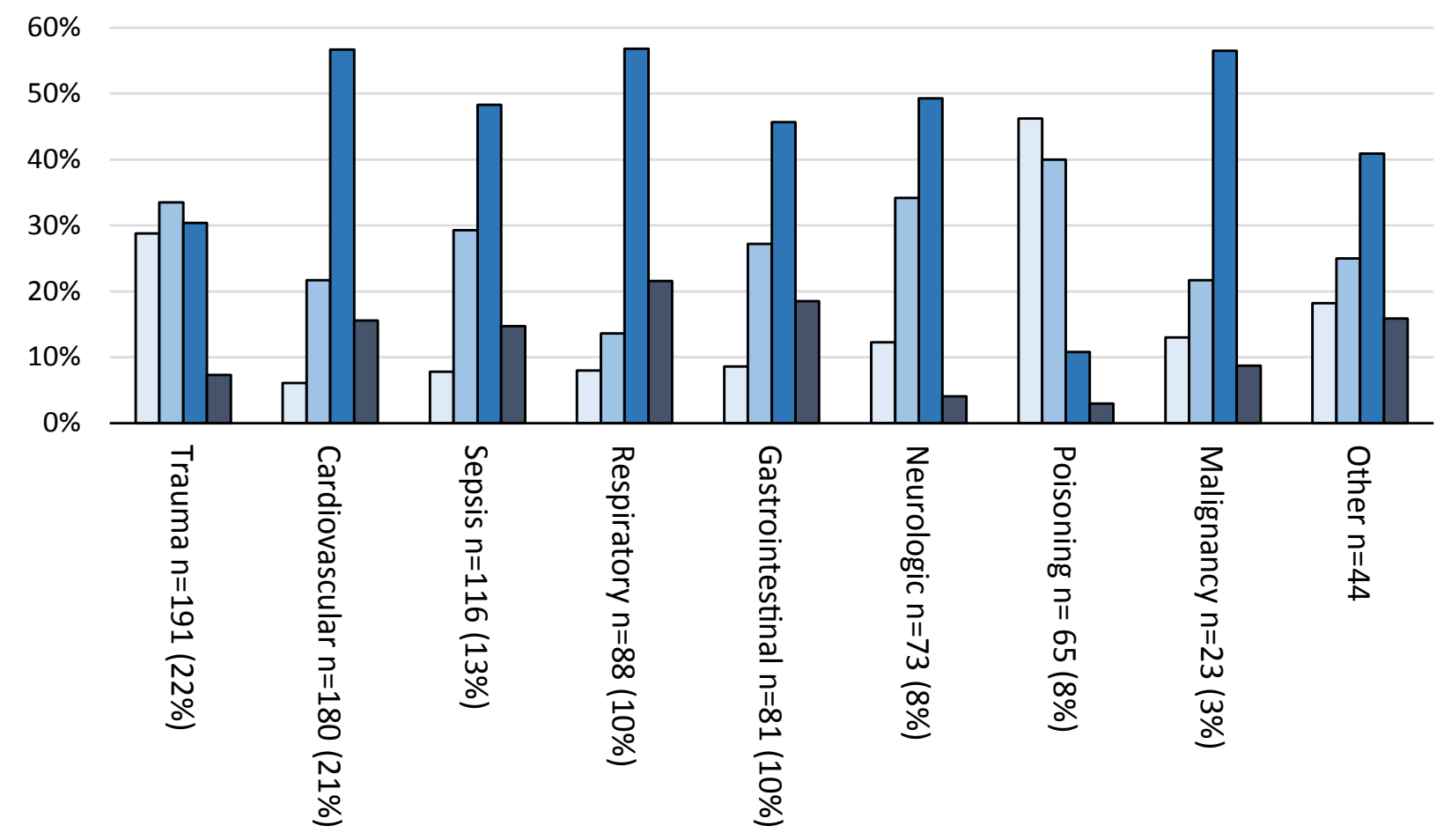

$\square$ 18-39 $\square$ 40-59 $\square 60-79 \square 80$ and above

Figure 3: Age distribution within diagnostic categories.

Table 5: Outcome.

\begin{tabular}{|c|c|c|c|c|c|}
\hline & \multirow[t]{2}{*}{ All patients $\mathrm{N}=861$} & \multicolumn{2}{|c|}{$18-59$ years $(n=377)$} & \multicolumn{2}{|c|}{60 years and above $(n=484)$} \\
\hline & & $\begin{array}{l}\text { Medical } \\
n=217\end{array}$ & $\begin{array}{l}\text { Surgical } \\
n=160\end{array}$ & $\begin{array}{l}\text { Medical } \\
n=320\end{array}$ & $\begin{array}{l}\text { Surgical } \\
n=164\end{array}$ \\
\hline ICU mortality $\mathrm{n}(\%)$ & $205(24 \%)$ & $38(18 \%)$ & $24(15 \%)$ & $94(29 \%)$ & $49(30 \%)$ \\
\hline Treatment restrictions, total $\mathrm{n}(\%)$ & $183(21 \%)$ & $27(13 \%)$ & $23(14 \%)$ & $85(27 \%)$ & $48(29 \%)$ \\
\hline Withdrawal of treatment $\mathrm{n}(\%)$ & $141(16 \%)$ & $21(10 \%)$ & $22(14 \%)$ & $60(19 \%)$ & $38(23 \%)$ \\
\hline _Treatment withheld n (\%) & $42(5 \%)$ & $6(3 \%)$ & $1(1 \%)$ & $25(8 \%)$ & $10(6 \%)$ \\
\hline Hospital mortality n (\%) & $279(32 \%)$ & $50(23 \%)$ & $28(17 \%)$ & $143(45 \%)$ & $57(35 \%)^{*}$ \\
\hline \multicolumn{6}{|l|}{$\begin{array}{l}\text { Discharge location for hospital } \\
\text { survivors: }\end{array}$} \\
\hline Home or rehabilitation n (\%) & $455(53 \%)$ & $146(67 \%)$ & $124(77 \%)$ & $111(35 \%)$ & $74(45 \%)$ \\
\hline _Nursing home n (\%) & $88(10 \%)$ & $10(5 \%)$ & $1(1 \%)$ & $55(17 \%)$ & $22(13 \%)$ \\
\hline $\begin{array}{l}\text {-Other (including } \\
\text { psychiatric institution) n (\%) }\end{array}$ & $39(4 \%)$ & $11(5 \%)$ & $7(5 \%)$ & $13(4 \%)$ & $11(7 \%)$ \\
\hline
\end{tabular}

ICU was almost twice as long for patients with surgical compared to medical admissions (6.2 vs. $3.5, p<0.05$ and 6.9 vs. 3.7, $p<0.01$ respectively). Separate analysis for intubated patients showed similar trends regarding length of stay (6.4 vs. 4.5 days, $p<0.05$ and 6.2 vs. $4.5, p=0.04)$, but no difference in median mechanical ventilator support time was seen between medical and surgical patients.

\section{Outcome}

Total hospital mortality was 279 (32\%) and ICU mortality was 205 (24\%) (Table 5). Decisions regarding limitations of life-sustaining treatments were made in $183 / 205$ (89\%) of the patients who died in the ICU. The proportion of patients with limitations of life-sustaining treatment was higher in surgical than medical patients in the age group $18-59(23 / 24,96 \%$ vs. $27 / 38,71 \%, p<$ $0.02)$. There were no such difference in patients older than 60 years or between the genders. ICU-mortality were similar for medical and surgical patients across the age groups (Table 5 ) and for male and female patients $(128 / 567,23 \%$ vs. $77 / 294,26 \%, p=0.23)$.

Presentation of hospital mortality with increasing age (Figure $4 \mathrm{a}$ and Figure $4 \mathrm{~b}$ ) showed different trends for medical and surgical patients. For medical patients (Figure 4a), the mortality increased steadily with age, but for patients 70 years and above, the curves for ICU and hospital mortality diverged. Among patients below 50 , the mortality curve peaks in the age group 30-39. In 


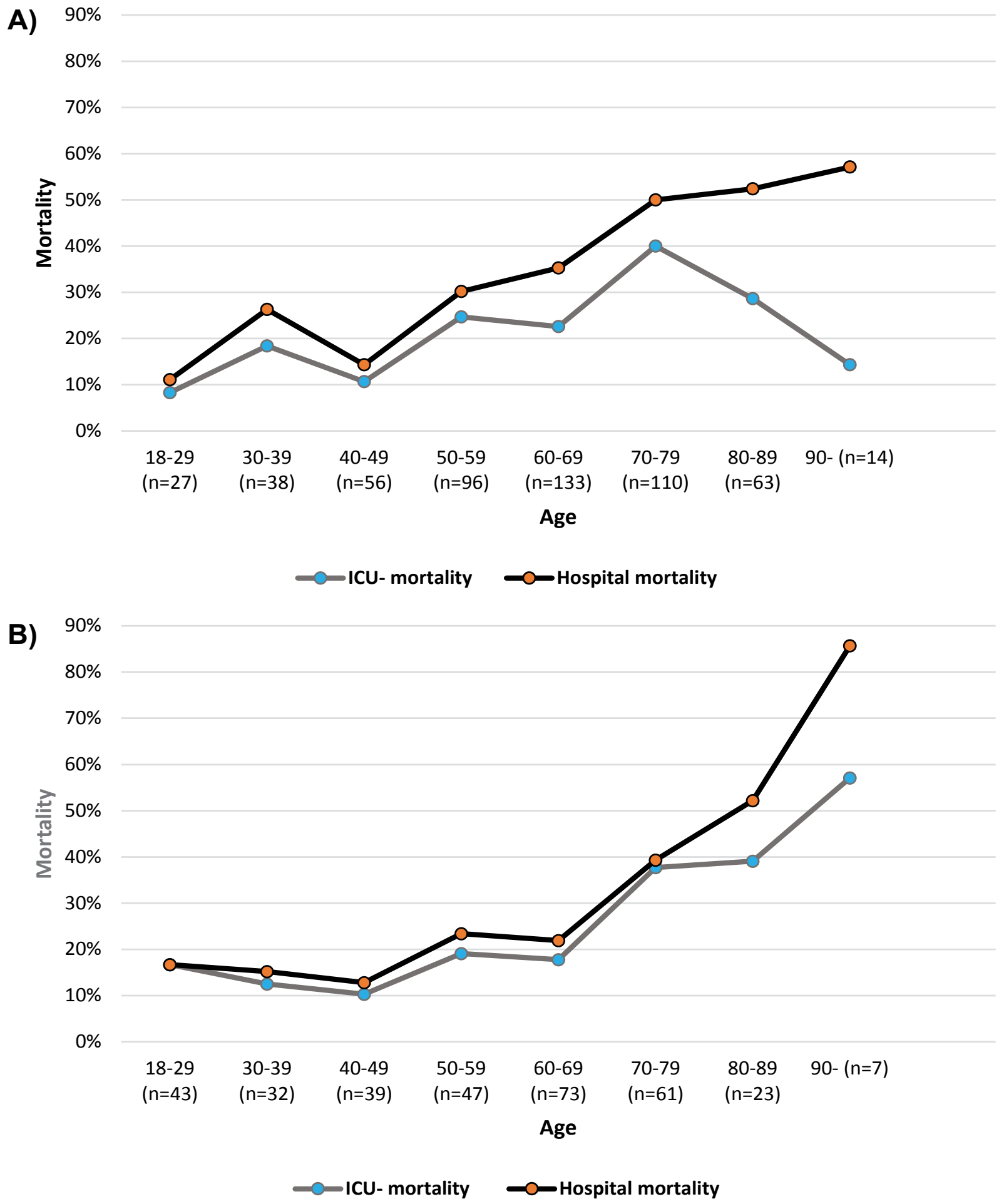

Figure 4: a) Hospital mortality with increasing age, medical patients $(n=537)$; b) Hospital mortality with increasing age, surgical patients $(n=324)$.

this age group $5 / 10$ deaths were caused by overdoserelated cardiac arrest. For surgical patients (Figure 4b), both the ICU- and hospital mortality were relatively stable until the age of 70 , from where it increased rapidly.

Comparison of medical and surgical patients showed a higher hospital mortality in medical patients in the age group above 60 (143/320, 45\% vs. 57/164, 35\%, $\mathrm{p}<0.05$ ), but not in the youngest age group (Table 5). Separate analysis of intubated patients showed a significantly higher hospital mortality among medical patients in both age groups $(43 / 152,28 \%$ vs. $28 / 158$, $18 \%, p<0.03$ and $84 / 164,51 \%$ vs. $55 / 158,35 \%, p<$ $0.01)$.

Within the diagnostic categories, patients with cardiovascular (100/180,56\%), gastrointestinal (28/81, $35 \%)$ and respiratory disease $(29 / 88,33 \%)$ had the highest hospital mortality rate. Patients with trauma $(41 / 191,22 \%)$ and poisoning $(9 / 65,14 \%)$ had the lowest hospital mortality (Table 6). 
Table 6: ICU and hospital mortality within diagnostic categories.

\begin{tabular}{|l|l|l|}
\hline Main diagnostic categories & ICU mortality $\mathbf{n}(\%$ of diagnostic category) & Hospital mortality n (\% of diagnostic category) \\
\hline Trauma & $34 / 191(18 \%)$ & $41 / 191(22 \%)$ \\
\hline Cardiovascular & $74 / 180(41 \%)$ & $100 / 180(56 \%)$ \\
\hline Sepsis & $20 / 116(17 \%)$ & $29 / 116(25 \%)$ \\
\hline Respiratory & $18 / 88(21 \%)$ & $29 / 88(33 \%)$ \\
\hline Gastrointestinal & $18 / 81(22 \%)$ & $28 / 81(35 \%)$ \\
\hline Neurologic/CNS & $23 / 73(32 \%)$ & $24 / 73(33 \%)$ \\
\hline Poisoning & $7 / 65(11 \%)$ & $9 / 65(14 \%)$ \\
\hline Cancer & $7 / 23(30)$ & $12 / 23(52 \%)$ \\
\hline Other & $4 / 44(16 \%)$ & $7 / 44(16 \%)$ \\
\hline Total & $205(24 \%$ of total) & $279(32 \%$ of total) \\
\hline
\end{tabular}

Of the 582 surviving patients, 455 (78\%) were discharged home or to rehabilitation, $88(15 \%)$ to nursing home, and 39 (7\%) were discharged to other locations including psychiatric institutions (Table 5).

\section{Discussion}

The present study describes preadmission characteristics, main causes of admission, treatment details and outcome of a large, mixed intensive care population in Oslo. Mean SAPS score was 46 , which is considerably higher than the average score of 38 reported by the Norwegian intensive care registry (NIR) in 2014 [10]. Almost three quarters of the patients received mechanical ventilation. Trauma and cardiovascular disease were the most common diagnostic categories, reflecting the regional function of the Oslo University hospital Ulleval as a tertiary referral hospital.

\section{Age and gender distribution}

Median age was 62, in line with median age for patients admitted to regional hospitals in Norway [10]. Two thirds of the patients were males, a significantly higher proportion than the 53\% male proportion among patients admitted to the Oslo University Hospital Ullevaal during the period. The high number of patients with trauma and cardiovascular disease may partly explain this finding. Nonetheless, males were in majority within all diagnostic categories and age groups, with the exception of the oldest patients (90+). This overrepresentation of males receiving intensive care treatment is in line with prior international studies $[11,12]$. Possible explanations are older age among the females and different pattern of disease manifestations for similar diagnoses for male and female patients. Nonetheless, a gender-biased decision-making process cannot be ruled out and should be investigated further.

Medical patients constituted two thirds of the study population. More than $90 \%$ of the surgical patients had non-scheduled surgical admissions. Inclusion of patients from postoperative units would have increased the number of patients with scheduled surgical admission. However, for this study we intended to study ICU patients with a high severity of illness, and therefore decided not to include postoperative units.

\section{Pre-admission characteristics}

Although the majority of patients had prior chronic disease, almost $80 \%$ of the patients were self-reliant without home care before admission. Thus, the majority of the patients had a relatively high level of function before admission. Comparison of the preadmission characteristics of medical and surgical patients showed several differences. Firstly, the proportion of self-reliant patients was significantly higher in surgical than medical patients across the age groups. Secondly, in the age group 18-59, surgical patients had significantly lower Charlson comorbidity index than medical patients, reflecting a much lower prevalence of pre-existing chronic disease. These findings suggests differences in predisposing factors for ICU admissions between medical and surgical patients that should be further investigated.

\section{Treatment}

A surprising finding was that surgical patients had almost twice as long median length of stay (LOS) in the ICU as medical patients, despite lower median age and less chronic disease. There are several possible explanations. Firstly, this difference is likely to reflect the vast resources needed in the treatment of severely ill trauma patients, including the need of repeated surgical procedures.

Secondly, among the patients who died in the hospital, a greater proportion of the surgical patients died in the intensive care unit as opposed to in medical patients where a higher proportion died at the ward (Figure $4 \mathrm{a}$ and Figure $4 \mathrm{~b}$ ). Other possible explanations are the high number of neurosurgical patients and the exclusion of postoperative patients.

\section{Mortality}

The high severity of illness and level of care of the study population was reflected in a hospital mortality rate of $32 \%$, almost twice as high as the average $17 \%$ mortality reported by NIR [10]. As expected, hospital mortality increased significantly by age, reflecting increased frailty, comorbidity and reduced ability of elderly patients to withstand acute disease. In patients older than 60 , medical patients had a higher hospital 
mortality. Interestingly, presentation of mortality within age groups showed different trends for medical and surgical patients. For surgical patients the mortality rate remained relatively low until the age of 70 , and then increased steeply. We consider the high proportion of trauma patients and the lower burden of comorbidity in the younger age groups of surgical patients as main explanatory factors. For medical patients, the intensive care mortality and the hospital mortality increased linearly until the age of 70 , but then diverged. This is in line with earlier findings [13] and reflects a shift towards dying at the ward instead of in the ICU among elderly intensive care patients.

For medical patients a peak in hospital mortality occurred for patients aged 30-39. Among the patients who died in this age group, half of the deaths were overdose-related cardiac arrests. Poisoning was the most common cause of admission in medical patients aged 18-59 and caused almost half of the admissions in patients younger than 40 years. These findings are in line with prior studies $[14,15]$, and confirm that substance abuse causes a significant proportion of preventable ICU-admission in young patients.

The association between trauma and substance abuse is well known $[16,17]$. Since trauma was the dominating diagnostic category among patients with surgical admissions, alcohol and drug exposure may have had an indirect influence on ICU admission in a significant proportion of these patients.

Limitations of life-sustaining treatment is common in European ICUs, but with substantial intercountry variability [9]. In our study population, limitations of life-sustaining treatments (as defined in the methods) occurred in almost $90 \%$ of the patients who died in the intensive care. This proportion is very high and surpasses the findings by Skjaker, et al. [18] in a study of end-of life-decisions in a Norwegian ICU-population. In comparison, our study population had a higher median age and severity of illness (SAPS II 46 vs. 42) and a different distribution of diagnostic categories including a much higher proportion of trauma patients. Our findings confirm the increased tendency of withholding and withdrawal of life sustaining treatment in the critically ill described in international studies [19], particularly in Nordic ICUs [9]. Of the hospital survivors, almost $80 \%$ were discharged to home or rehabilitation, indicating a low prevalence of futile intensive care treatment.

\section{Strengths and limitations}

The patient cohort in the present study is large, and contains intensive care patients from many specialties. Data was collected prospectively and the registrations were made by a small number of study personnel. The present study conveys a comprehensive set of descriptive data particularly regarding pre-admission characteristics of the intensive care population.
Comparison of medical and surgical patients within age groups is a strength because it allowed detection of subtle differences between the subgroups.

Evaluation of ICU services is challenging due to variations in ICU-beds availability and case mix between different intensive care populations. This is a limitation when trying to generalize the findings of this study to other populations or settings.

In order to simplify the analysis, patients with scheduled and non-scheduled admissions were described as one group. This merging represents a possible limitation since there may be I differences in the characteristics of these patients.

\section{Conclusions}

1. In the age group 18-59 years, medical patients had a considerably higher prevalence of pre-existing chronic disease score compared to surgical patients, suggesting differences in predisposing factors. Trauma and poisoning were the most common causes of admissions. Since these diagnostics categories represent possibly preventable ICU-admissions, more focus on preventive efforts is needed.

2. In the age group 60 and above, comorbidity was similar in medical and surgical patients. Nonetheless medical patients had higher hospital mortality. While the majority of surgical patients within this age group died in the ICU, medical patients had a tendency of dying at the ward.

3. Limitations of life-sustaining treatment were made in almost $90 \%$ of the patients who died in the ICU, and the vast majority of the surviving patients were discharged home or to rehabilitation. This indicates a low prevalence of futile treatment.

\section{Acknowledgements}

Thanks to the nurses and medical staff at the ICUs at the Oslo University Hospital Ulleval and The Diakonhjemmet Hospital for their cooperation and help with the inclusion of patients during the study period.

\section{References}

1. Laake JH, Dybwik K, Flaatten HK, Fonneland IL, Kvale R, et al. (2010) Impact of the post-World War II generation on intensive care needs in Norway. Acta Anaesthesiol Scand 54: $479-484$

2. Martin G (2006) Epidemiology studies in critical care. Crit Care 10: 136.

3. Garland A, Olafson K, Ramsey CD, Yogendran M, Fransoo $R$ (2014) Distinct determinants of long-term and short-term survival in critical illness. Intensive Care Med 40: 10971105.

4. Piccirillo JF, Vlahiotis A, Barrett LB, Flood KL, Spitznagel $E L$, et al. (2008) The changing prevalence of comorbidity across the age spectrum. Crit Rev Oncol Hematol 67: 124132.

5. Murthy S, Wunsch H (2012) Clinical review: International 
comparisons in critical care - lessons learned. Crit Care 16: 218.

6. Charlson ME, Pompei P, Ales KL, MacKenzie CR (1987) A new method of classifying prognostic comorbidity in longitudinal studies: development and validation. J Chronic Dis 40: 373-383.

7. Le Gall JR, Lemeshow S, Saulnier F (1993) A new Simplified Acute Physiology Score (SAPS II) based on a European/ North American multicenter study. JAMA 270: 2957-2963.

8. Vincent JL, Moreno R, Takala J, Willatts S, De Mendonca A, et al. (1996) The SOFA (Sepsis-related Organ Failure Assessment) score to describe organ dysfunction/failure. On behalf of the Working Group on Sepsis-Related Problems of the European Society of Intensive Care Medicine. Intensive Care Med 22: 707-710.

9. Sprung $\mathrm{CL}$, Cohen SL, Sjokvist $\mathrm{P}$, Baras $\mathrm{M}$, Bulow $\mathrm{HH}$, et al. (2003) End-of-life practices in European intensive care units: the Ethicus Study. JAMA 290: 790-797.

10. https://helse-bergen.no/norsk-intensivregister-nir/ arsrapportar

11. Valentin A, Jordan B, Lang T, Hiesmayr M, Metnitz PG (2003) Gender-related differences in intensive care: a multiplecenter cohort study of therapeutic interventions and outcome in critically ill patients. Crit Care Med 31: 1901-1907.

12. Andersen FH, Kvale R (2012) Do elderly intensive care unit patients receive less intensive care treatment and have higher mortality? Acta Anaesthesiol Scand 56: 1298-1305.

13. Lund C, Teige B, Drottning P, Stiksrud B, Rui TO, et al. (2012) A one-year observational study of all hospitalized and fatal acute poisonings in Oslo: Epidemiology, intention and follow-up. BMC Public Health 12: 858.

14. Cretikos MA, Parr MJ (2003) Drug related admissions to intensive care: the role of illicit drugs and self poisoning. Crit Care Resusc 5: 253-257.

15. Bogstrand ST, Gjerde H, Normann PT, Rossow I, Ekeberg O (2012) Alcohol, psychoactive substances and non-fatal road traffic accidents--a case-control study. BMC Public Health 12: 734.

16. Moore EE (2005) Alcohol and trauma: The perfect storm. J Trauma 59: 53-56.

17. Skjaker SA, Hoel H, Dahl V, Stavem K (2017) Factors associated with life-sustaining treatment restriction in a general intensive care unit. PLoS One 12: e0181312.

18. Prendergast TJ, Luce JM (1997) Increasing incidence of withholding and withdrawal of life support from the critically ill. Am J Respir Crit Care Med 155: 15-20.

19. Bagga A, Bakkaloglu A, Devarajan P, Mehta RL, Kellum JA, et al. (2007) Improving outcomes from acute kidney injury: report of an initiative. Pediatr Nephrol 22: 1655-1658. 


\section{Appendix}

Inclusion criteria $\geq 18$ years and

1. Intubation regardless of length of stay and/or

2. ICU length of stay $\geq 24$ hours and/or dysfunction of $\geq$ two organ systems

Definition of organ dysfunction: Based on definitions for acute organ failure in sepsis [20]. ${ }^{*}$ The value was set equivalent to a SOFA score [8] of $\geq 2{ }^{* *}$ For renal dysfunction the definition was based on AKIN criteria level $\geq 1$. ${ }^{* * *}$ Liver dysfunction was defined based on the Child-Pugh score.

\begin{tabular}{|c|c|c|}
\hline Organ system & Definition of dysfunction & Source \\
\hline Respiration & $\mathrm{PaO}_{2} / \mathrm{FiO}_{2}<33 \mathrm{kPa}$ & Sepsis criteria \\
\hline Cardiovascular & Need for vasopressor to obtain MAP $\geq 70 \mathrm{mmHg}$ & Sepsis criteria \\
\hline Metabolic & $\mathrm{pH} \leq 7.3$ or $\mathrm{BE} \geq 5$, and lactate $>3 \mathrm{mmol} / \mathrm{L}$ & Sepsis criteria \\
\hline $\mathrm{CNS}^{*}$ & GCS $\leq 12$ & Sepsis criteria/SOFA score \\
\hline Hematological $^{*}$ & Platelets $<100 \times 10^{9} / \mathrm{L}$ & Sepsis criteria/SOFA score \\
\hline Liver $^{* * *}$ & Bilirubin $\geq 34 \mu \mathrm{mol} / \mathrm{L}$ or INR $\geq 1.7$ & Sepsis criteria/Child Pugh \\
\hline Renal $^{* *}$ & $\begin{array}{l}\text { Urin output }<0.5 \mathrm{ml} / \mathrm{kg} / \mathrm{hr} \times 6 \text { hour } / \text { increased creatinine } \times 1.5 \mathrm{mg} / \mathrm{L}(\geq 26.4 \\
\mu \mathrm{mol} / \mathrm{L})\end{array}$ & Sepsis criteria/AKIN score \\
\hline
\end{tabular}

